\title{
Analyzing the Effectiveness of Vocabulary Knowledge Scale on Learning and Enhancing Vocabulary through Extensive Reading
}

\author{
Syeda Asima Iqbal ${ }^{1} \&$ Syeda Anila Komal ${ }^{1}$ \\ ${ }^{1}$ Department of English, NCBA \& E, Lahore, Pakistan \\ Correspondence: Syeda Asima Iqbal, Department of English, NCBA \& E, Lahore, Pakistan. E-mail: \\ asima.imran@yahoo.com
}

Received: July 5, 2017 Accepted: August 1, 2017 Online Published: August 3, 2017

doi: 10.5539/elt.v10n9p36 URL: http://doi.org/10.5539/elt.v10n9p36

\begin{abstract}
This research is about the effectiveness of Vocabulary Knowledge Scale after extensive reading which helps in the enhancement of global language skills especially their vocabulary. This research is an endeavor to create an awareness of its significance in language acquisition through extensive reading especially focusing on vocabulary. The Vocabulary Knowledge Scale and interviews were the data collection tools. On the basis of analysis and interpretation, it was understood that Vocabulary Knowledge Scale was helpful in measuring vocabulary of the students and showed improvement in their vocabulary. This research also exposed many weaknesses of the administration and teachers. Further, it became clear that at the moment the problem was of insufficient training of teachers to motivate their students and be the best role models. Administration and teachers both need to show willingness to motivate students to develop reading habits.
\end{abstract}

Keywords: extensive reading, vocabulary knowledge scale, comprehension skills, graded readers

\section{Introduction}

The value of reading in education trails back to the very start of the printed words and learning. Reading has been a fundamental element of learning essential language skills for beginners. Nuttal (1982) mentions that reading skills and vocabulary can be improved by extensive reading. This activity builds vocabulary and expands it further through exposure to a large variety of words to understand and figure out their meanings and retain them for a longer period of time. Vocabulary is learned by exposure to words over and over again in order to achieve long term memory retention. Through extensive reading words are exposed to the reader a number of times to retain in the minds of learners by using graded readers. It is also helpful for the learners when they read words in context where meanings become clearer or they can infer the meanings of unfamiliar words. Hoey (2005) presented a theory of 'lexical priming' which supports the notion of exposure to language items in context to the learners for long term memory retention. In addition, it boosts interest from participants when they choose books of their own choice to read and it develops their interests towards reading. Teachers are not the overall controllers of learning as it takes place outside of the classroom as well. Another benefit is that all students are free to choose their own books and even low ability students will not feel embarrassment in choosing books and progressing along with the high achievers. Students will not be depressed or less motivated and the overall impact of extensive reading will be positive. Moreover, students become independent readers with more motivation and encouragement to read and understand.

Multiple exposures to individual words can lead to better memory retention. Day and Bamford (1998) advocated that it also helps in the development of sight vocabulary or recognition of words automatically without help or thinking. This means that fluency, reading speed and language processing increases along with all other language skills. Mutoh, Bamford and Helgesen (1998) quoted Grabe (1995) that extensive reading supplements reading program in 1991, he further summed up that there are many benefits of reading if it is extensive. In addition, if silent reading is done for a longer period of time it can enhance vocabulary and grammatical skills which further promotes confidence. Comprehension skills of the learner also expand and the leaner becomes a more independent reader. Laufer (1989) argues that $95 \%$ of words that are present in the text should already be known to the learner to understand it properly. If there are many unfamiliar words in the text, it would be hard for the learners to comprehend it and they can lose their interest. To conclude, extensive reading can broaden the horizon and one can see the world seen through a different perspective. 


\subsection{Statement of the Problem}

Stahl (2005) emphasized that vocabulary instruction should provide students with opportunities to encounter words repeatedly and in a variety of contexts. Furthermore, there are varieties of strategies to teach vocabulary but there is still no proof from any research which shows the best method of teaching and learning vocabulary. The current study discusses expanding vocabulary through extensive enjoyable reading and vocabulary enhancement was measured through a Vocabulary Knowledge Scale. In the past, traditional teaching methods have developed a dislike for reading among students and they could not connect pleasure with reading. Vocabulary learning through vocabulary related activities have not been used regularly in the classroom. This research has made an effort to analyze vocabulary enhancement through extensive reading and related activities.

\subsection{Objectives of the Study}

The objectives of the present study are:

1) To analyze the logical relationship of vocabulary with other words by comparing participants' Vocabulary Knowledge Scale before and after extensive reading at elementary level

2) To find out the retention of vocabulary through active engagement via Vocabulary Knowledge Scale

3) To explore participants' enjoyment and curiosity about reading through interview

\subsection{Research Questions}

This study has following questions of research:

1) How does extensive reading help students in enriching their vocabulary through active engagement in variety of activities?

2) How do students retain vocabulary and utilize them in their writings after extensive reading and related activities?

\subsection{Significance of the Study}

There are two main reasons why an extensive reading approach is particularly justified and useful for students. Firstly, students are English majors and their future careers are likely to be language teaching or in areas where this language is widely used and their planned future studies are related to this field. Therefore, extensive reading can help students to gain highly skilled reading comprehension abilities. Secondly, extensive reading helps students become fluent English readers and as a result, there are improvements not only in linguistics, but from a psychological and educational approach as well. For that reason, extensive reading is the solution to achieve global language skills. Day (2011) emphasized that "the more our students read, the better readers they become' and learn new vocabulary. It is obvious that extensive reading plays a key role in vocabulary development, which is considered an indispensable part in the acquisition of a second or foreign language. Such research strongly supports the evidence that vocabulary growth can occur incidentally through extensive reading.

\subsection{Limitations of the Study}

1) The data for the study was only collected from an elementary school.

2) This study was limited to assess only the vocabulary of the students of the eighth grade.

3) The sample was only taken from one government English school of Bahawalpur, Pakistan.

\subsection{Justification of the Study}

Vocabulary knowledge enhances comprehension skills. There is strong relationship between vocabulary and comprehension, which has been proven by many studies. Studies of extensive reading have identified positive impacts of extensive reading on L2 reading abilities and vocabulary (Pigada \& Schmitt, 2006; Webb \& Chang, 2015). This study has focused on the enhancement of students' vocabulary through extensive reading and related vocabulary activities. Inside the language classroom, many strategies can be used to enhance vocabulary but few of them are very effective. In this study, extensive reading was done with a focus on improving vocabulary of students and later on measured by a Vocabulary Knowledge scale.

\section{Literature Review}

It was believed during the mid 1980s that reading skills and vocabulary develops when learners are exposed to enormous amount of comprehensible input which is enough to cause language acquisition. Krashen (1989) suggests that the learners can acquire new vocabulary and develop their spelling ability through maximum exposure of "comprehensible input" through extensive reading. In addition, Krashen (1993) also mentions that extensive reading is the most efficient way through which a learner can learn new vocabulary. Reading helps 
expose students to many words which are not only high frequency but low as well. Students read a large variety of interesting text without getting help from other people. "Time on text" will have a maximum payoff in terms of helping students learn words. The more children read book or reading materials of their own choice on their own, the more words they come across and the more word meanings they can understand and learn. Another way to increase English language learners' experience is to promote wide or incidental reading. Although the National Research Panel (2000) concluded that there is a lack of evidence that wide reading enhances vocabulary learning, Cunningham (as cited in Blachowicz et al., 2006) refuted it, arguing that out-of-school reading contributes greatly to vocabulary learning. In fact, reading volume has been demonstrated to be a strong predictor of vocabulary differences (Cunningham \& Stanovich, 1998).

\subsection{Extensive Reading vs. Intensive Reading}

According to Bamford (1987), intensive reading is done through reading short but challenging texts complete and precise understanding in the end. On the other hand, extensive reading is a short but easy text that is read mostly outside of the classroom and only two or three unknown words per page do not let student lose their interest. Students are free to choose the text for their own learning and can stop reading if they do not like it. The students do not feel pressure as they choose their reading time and place. Bamford and Day (2004) stated that the key elements of extensive reading are the purpose and pleasure of the learner. On the other hand, intensive reading teaches students important skills such as sequencing, ordering, identifying the main idea or reading for gist etc. A lot of material is chosen to understand the text rather going into the details and meanings of all individual words. Intensive reading requires short texts but a detailed understanding of every item present in the text.

\subsection{Kinds of Extensive Reading}

In most extensive reading programs students are allowed to choose books of their own choice and level. So at the same time they read different books in their own 'comfort zone' according to their fluency level. Maley (2009) suggested that individual reading is also called Sustained Silent Reading (SSR) or Drop Everything and Read (DEAR).

Firstly, the selection of books is mostly chosen under the guidance of teachers to choose the right level which is later on read either at school or taken home for reading. There are some courses which offer students to read the same book containing many chapters over several lessons in the class together or as homework. Teachers plan prereading activities for this type of lessons like teaching few key words or prediction of the content. Discussions and comprehension questions are mostly done after this reading. It will be considered as extensive reading if students are reading quickly with no stress and understanding without using dictionary. If students really want to benefit from extensive reading they must read at the right level to practice reading and need good speed which is $150-200$ words per minute or a little less for students at a beginner level. This rate is supported by Nuttall (1996), who stated that "for an L1 speaker of English of about average education and intelligence... the reading rate is about 300 words per minute" (p. 56).

\subsection{The Extensive Reading Procedure in Practice}

Although the literature is questionable or conflicting on several points extensive reading in practice is uncomplicated enough. Richards and Rodgers (1982) describe 'procedure' as the techniques, practices, and activities that operate in teaching and learning a language according to a particular method. This is expressed in terms of

(a) Teachers' strategies and tactics

(b) Exercises and practice activities

(c) Various resources in terms of time, space, and equipment.

\subsection{Techniques and Tactics}

According to Hedge (1985) in the "reader interview", the role of teacher is to encourage and guide the student during reading and after reading in discussions after or during class time. Comments should be given through written summaries after reading and proper checking should be done. Oral or written summaries give students a chance to express that reading is being done. It also help teacher to understand the reading level of the student. If students are not at the acceptable reading level, teacher can guide them to the appropriate level of reading (Susser \& Robb, 1989). Students must be given proper channel to write summaries at the start of the course they may need to be guided a lot. A review of summaries can be done by the teacher moving among the students while they are involved in different activities. Teachers can check copies in their free time to keep a check on students learning. 


\subsection{Exercises and Practice Activities}

Smith (1988) have proved that although the main task of the reader is to improve reading skills summary writing can help teachers gauge the students' comprehension level as writing leads to improvements of comprehension. This writing practice helps students progress in their writing ability (Robb \& Susser, 1989). It is further stated that 'standard exercise,' with open-ended questions can be given after extensive reading which match the course books of the students as well. There is also a responsibility of the students to find out the suitability and comprehensibility of the books they read.

\subsection{Resources}

The main resources of extensive reading are a large collection of books and magazines and a place to put them properly. Otherwise, students will either have to buy books themselves or get them issued from public libraries which is difficult for ESL students. The main obstacles in the implementation of the extensive reading procedure are financial or logistical problems. Providing books to students is not enough only because the key objective of extensive reading is to read maximum number of books. The amount of books should be set for the students per week to measure students' progress and the improvement in their language level. Difficulty 'weighted page' has been set as a standard unit which includes format, type size, and number and size of illustrations vary widely (Susser \& Robb, 1989).

\section{Research Methodology}

\subsection{Research Design}

The purpose of this study was to find out the effectiveness of a Vocabulary Knowledge Scale on the enrichment of vocabulary through extensive reading. The main objective was to analyze the improvement of vocabulary after extensive reading by comparing the Vocabulary Knowledge Scale results before and after extensive reading. This research used a mixed method approach where interviews from students and teachers were qualitative and the Vocabulary Knowledge Scale was quantitative in nature.

\subsection{Population}

There were sixty two English schools in Bahawalpur (Pakistan) where the population of grade eighth students was approximately 2480 students and 248 English language teachers. In this study, participants consisted of both females and males. Their ages ranged from 12-15 years.

\subsection{Sample}

In the first step, through convenient sampling, two schools were selected. Next, the students for this study were picked randomly. The sample was chosen from grade eighth students who were studying General English as a compulsory subject. Out of a population only 100 students were selected where both 50 boys and 50 girls took part. 20 language teachers and 4 head teachers, who were selected randomly, were also part of this research.

\subsection{Research Tools}

This type of research needed a detail study so interviews and a Vocabulary Knowledge scale were used as research tools.

\subsubsection{Vocabulary Knowledge Scale (VKS)}

For this research, the vocabulary knowledge scale was used which was developed by Paribakht and Wesche (1993). The purpose of this scale was to measure the enhancement of vocabulary through extensive reading. The test is a 5-point scale report and performance items are used to obtain demonstrated and self-perceived knowledge of specific vocabulary words usually in written form. The scale ratings range from entire unfamiliarity, little recognition of the word, little idea of its meaning and to the ability to actually use the word in context with grammatical and semantic accuracy. The scale basically measures the progressive degrees of vocabulary knowledge. Level I tell what learners do not know whereas next three levels, II, III, and IV measure the vocabulary recognition. The levels measure the actual use of word in a sentence which is called productive vocabulary. When participants give evidence of their knowledge, the score given to that test item is then determined by a relocation of scores according to the categories explained below. The participants were given target words lists and explained how to demonstrate their level of knowledge for each, and for self-report levels IV and V, to show this knowledge. VKS scoring allows categories I and II to give scores 1 and 2 for self reported word knowledge but needs a display of knowledge for higher scores. Score 2 was given to categories III, $\mathrm{IV}$ and $\mathrm{V}$ for incorrect responses in the self-report. For correctly identifying synonyms or meanings score 3 was awarded for categories III and IV. If words had been used in the right context but with wrong grammar then Score 4 was given. Score 5 was given where the vocabulary word was used correctly grammatically and 
semantically.

Test 1: $000111223233444555=45 / 18=2.5$

Test 2: $134011522341154354=49 / 18=2.7$

Paribakht and Wesche (1993) determined the reliability of the VKS through testing and retesting of a word list (contained $\mathrm{N}=32$ ) to 93 different participants with 6 different proficiency levels. The VKS sheet with thirty vocabulary words was given to the participants at the start of the program. They had to put a tick in front of the option they think is right. There were five options in front of each word. This scale helped the researcher to find out the vocabulary level of the participants before starting the ER program. To establish learner's overall vocabulary size after the completion of the program, VKS was used once again where participants had to tick the options given in front of the vocabulary words which were counted or measured later according to the scale. Finally, these two scales were compared to find out the enhancement participants' vocabulary. They were part of this ER program for twelve weeks and words were repeated in graded readers many times. Many activities after reading also helped participants in long term memory retention.

\subsubsection{Interviews}

Qualitative interview was used where informal spontaneous conversation took place with the participants. The purpose of using interview was to provide supplementary evidence to make the research more valid. Participants were also interviewed at the end of the program to check their attitudes towards extensive reading and learning. Teachers' interviews were also important as their views could make a difference not only for future implementation of extensive reading program but also their interest and motivation would help participants to carry out such a program for the betterment of the students. 20 language teachers and four head teachers were interviewed based on loosely structured. The interviews were informal to avoid a reactive effect.

\subsection{Data Analysis}

\subsubsection{VKS Analysis}

Participants of the research took VKS test before and after the extensive reading twelve week program and data was analyzed quantitatively.

Table 1. Word Categories in VKS

\begin{tabular}{llllll}
\hline S. No. & VKS & Verbs & Nouns & Adjectives & Total Words \\
\hline 1. & Pre VKS & 6 & 17 & 6 & 30 \\
2. & Post VKS & 5 & 12 & 12 & 30 \\
\hline
\end{tabular}

VKS sheet with thirty vocabulary words were given to the participants in the start of the program. They had to put a tick in front of the option they think is right. There were five options in front of each word. The method of measuring vocabulary through VKS has been mentioned above in the same chapter under vocabulary scale knowledge. This scale helped the researcher to find out the vocabulary level of the participants before starting the extensive reading. To establish learner's overall vocabulary size after the completion of the program, VKS had been used once again where participants had to tick the options given in front of the vocabulary words which were counted or measured later according to the scale.

Finally, these two scales were compared to find out the enhancement participants' vocabulary. They were part of this extensive reading program for twelve weeks and vocabulary words were repeated in graded readers many times. Many activities after reading also helped participants in long term memory retention.

The results showed that initially participants were not familiar with many words given in the word list. Many students had seen those words before but never had a chance to use it. There were very few participants who could not only understand the words but could use them properly in the context. There were 40 words in the list and participants were given enough time to think and select the options given in front of each word. The results of pre- and post VKS are as follows: 
Results of pre and post VKS are as follows:

Table 2. Pre and post result of VKS

\begin{tabular}{lllllll}
\hline S.no. & $\begin{array}{l}\text { Number of students in } \\
\text { pre-VKS [f] }\end{array}$ & $\begin{array}{l}\text { Mean of Pre } \\
\text { VKS [x] }\end{array}$ & & $\begin{array}{l}\text { Number of students in } \\
\text { post VKS [f] }\end{array}$ & $\begin{array}{l}\text { Mean of post } \\
\text { VKS [x] }\end{array}$ & fx \\
\hline 1 & 5 & 1.2 & 6.0 & 7 & 1.3 & 9.1 \\
2 & 19 & 1.3 & 24.7 & 13 & 1.4 & 18.2 \\
3 & 14 & 1.5 & 21.0 & 16 & 1.6 & 25.6 \\
4 & 8 & 1.6 & 12.8 & 11 & 1.8 & 19.8 \\
5 & 4 & 1.8 & 7.2 & 3 & 2.0 & 6.0 \\
& 50 & & 71.7 & 50 & & 78.7 \\
\hline
\end{tabular}

Mean of Pre VKS $=\sum \mathrm{fx} / \sum \mathrm{f}$

$$
=71.7 / 50=1.434
$$

Mean of Post $\mathrm{VKS}=\sum \mathrm{fx} / \sum \mathrm{f}$

$$
=78.7 / 50=1.574
$$

Difference of mean $=1.574-1.434=0.14$

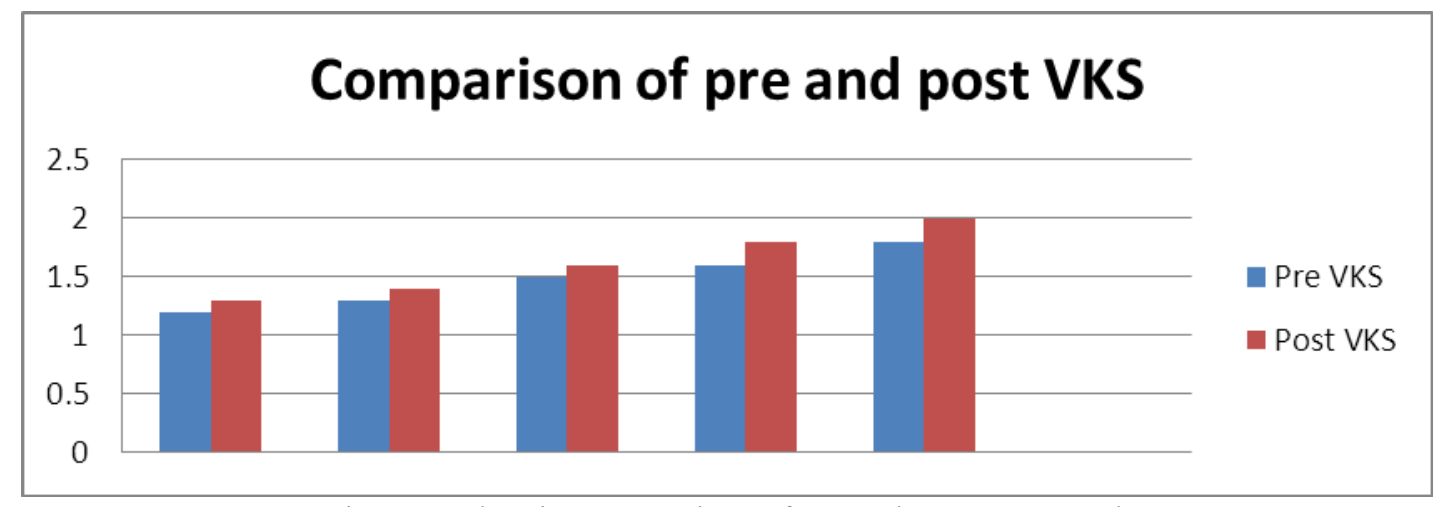

Figure 1. Showing comparison of pre and post VKS results

According to the results, there was a difference of at least 0.14 in the mean of all participants. There is really a big change in the VKS of participants where it seems that there is increase in the understanding of the new words. Many words which were previously unknown to the participants became known or were at least in the, "I have seen before" category. There were many participants who knew the meaning of many words and could use them in sentences also. Many participants were able to understand the vocabulary but there were a few who were confused about the right usage of those words. This shows that extensive reading had helped participants in the enhancement of their vocabulary. As twelve weeks are not enough to observe big changes in attitudes or habits but it is useful in that the participants can at least realize the importance of reading extensively. These results provide evidence that extensive reading can enhance vocabulary and participants learned many new words which during reading and after reading activities were reinforced.

To measure the vocabulary enhancement, two tests were taken from the research participants. In this study, the data collected from subjects' performances for the three tests were analyzed to see whether vocabulary learning through reading approach enhanced learners' vocabulary. To examine the amount of vocabulary knowledge, both descriptive statistics and inferential statistics for three measures were used. In short, the results of the tests were compared and analyzed in terms of comparing the mean (X) and standard deviation (SD) conducting One Way Repeated Measures ANOVA using the Statistical Package of Social Science (SPSS) software. Tables and charts were used to illustrate the trend and relationships among data. 
Table 3. The results of descriptive statistics for three test types for immediate test (test 1)

\begin{tabular}{lllllll}
\hline Tests & & & & & & $\begin{array}{l}95 \% \text { confidence } \\
\text { interval of difference }\end{array}$ \\
\hline & $\mathrm{N}$ & Mean & S. Deviation & SD Error & Lower & Upper \\
$\begin{array}{l}\text { Word_Form } \\
\text { Recognition }\end{array}$ & 50 & 14.88 & 3.15 & 0.44 & 13 & 17 \\
$\begin{array}{l}\text { MC Recognition } \\
\text { Translation }\end{array}$ & 50 & 14.52 & 2.71 & 0.38 & 12 & 18 \\
\hline
\end{tabular}

Note: $\mathrm{P}$ for all analyses, $\mathrm{p} \leq .05$.

Table 3 displays the total scores for test 1 . The results show a vocabulary gain of the mean score of 14.8 for the word form recognition test, the mean score of 14.52 for the multiple choice test, and the mean of 11.64 for the translation test. The mean scores for all three test types indicate a gain in the students' vocabulary knowledge through the incidental vocabulary learning approach. This finding also supports the result of the study by Brown et al., (2008) that indicated incidental vocabulary occurs through reading.

The table also shows that the highest gains were achieved in word-form recognition test. The score for the Multiple Choice (MC) recognition test was half of the word-form recognition test. The lowest score obtained belongs to the translation test. From the data it could be found which type of test was easier or more difficult for the learners.

Word form recognition test seems to have been easier for them and meaning translation test the most difficult. The results for word-form recognition test show that substantial $36 \%$ of 25 words were learned. This suggests that the highest vocabulary gain, across all tests, was obtained from word-form recognition test.

Table 4. The results of Descriptive Statistics for three test types for immediate test (test 2)

\begin{tabular}{lllllll}
\hline Tests & & & & & & \multicolumn{2}{c}{$\begin{array}{c}\text { confidence } \\
\text { interval } \\
\text { difference }\end{array}$} \\
\hline & & & & & Lower \\
Word Form Recognition & 50 & 15.84 & 3.01 & 0.42 & 13 & 18 \\
MC Recognition & 50 & 15.64 & 2.70 & 0.38 & 14 & 18 \\
Translation & 50 & 13.14 & 2.92 & 0.41 & 11 & 15 \\
\hline
\end{tabular}

Note: $\mathrm{P}$ for all analyses, $\mathrm{p} \leq .05$.

\subsubsection{Interview Analysis}

Interviews from students showed that there is lot of curriculum pressure on them and as a result they are unable to read extensively. Though, they read sometimes but they are not encouraged by the teachers due to time constraint. According to one student, some parents and teachers consider extra reading as a waste of time and that reading extra material can contain immoral texts which is not healthy for students. Teachers were of the opinion that they needed lots of resources and help from the administration for extensive reading. They did agree to the fact that they needed proper training to help students during activities and reading time. Resources could make the task easier if provided by their schools. Teachers are of the opinion that it should be linked with intensive reading and both extensive and intensive together could help participants more than focusing on only one method because there is syllabus pressure on them and it has to be covered on time and assessed. If both intensive and extensive reading both are linked in a syllabus in such a way that it not only covers the syllabus but enhances global learning that would bea good outcome. One teacher suggested that sometimes if there are insufficient resources and less cooperation from the administration, to lessen the impact of such programs parents who can afford resources can donate to the school or even donate money to buy things according to individual school needs. It is not only the duty of parents but also wealthy community members to participate in 
such causes and programs through donations to bring a change in their society. One of the problems highlighted was that the teachers also need to be trained for such effective programs. As teachers are role models for students and they are unable to guide and facilitate students, the main purpose of any program goes waste and all efforts are futile. Teachers should be given proper training by already well-trained people. Another observation was that syllabus of school can be too demanding and instead of learning and understanding, most of the student time is wasted on covering many topics. It was suggested that the syllabus needs to be revised and should be reduced but it should have contents that covers all necessary knowledge.

\section{Findings and Discussions}

The purpose of current study was to explore the impact of extensive reading on vocabulary enhancement. For that reason, few research questions were made to achieve the objectives of this research.

\subsection{Findings}

According to Table 4 (above), the results indicate that improvement in the performance of participants and the difference of mean was 0.14 . Though this twelve week program was insufficient to help the participants in memorizing or retaining all words present in the graded readers, it was evident that if healthy extensive reading is done, it can bring positive changes to students' learning. So, according to these results, the researcher has achieved the first objective of the research and found the answer of first question as affirmative. Oxford graded readers were used for extensive reading as vocabulary words keep on repeating in every level and maximum exposure of words lead to permanent retention in the minds of the learners. Post VKS results also supported this answer. Students develop interest in reading only if the book their reading is at correct level, is considered interesting and a healthy atmosphere is provided to them to retain learned things such as vocabulary to achieve language competency. For that purpose graded readers were provided to the participants and in a constructive way teachers conducted after reading activities and kept observing the behaviour and performances of all the participants. Bamford (1987) stated that graded readers are appropriate language learner literature. Graded readers help in enhancing reading speed, understating, improving knowledge, fluency and not only working with words but working with ideas (Waring, 2009). According to the findings for the questions, the second objective has been achieved. In the interviews, teachers supported the same idea that it was the interesting activities that attracted participants to read and get involved in them. Most of students enjoyed it and wanted the program to be continued. From all these findings, the researcher has achieved third objective and supported the fourth question of the research as well. To conclude, extensive reading helps participants in learning and enhancing new vocabulary words in an interesting way. This has been proven correct by the findings of this research. Secondly, students retain words and use them in their writings through extensive reading'. Repetition of the vocabulary words during reading help in their retention and the books of participants' reading level and interest motivate them to read more next time and the students find extensive reading enjoyable.

\subsection{Discussion}

It is expected that schools will astutely utilize the results of this research and accordingly gain the benefits of extensive reading programs in the institutions. It is also supposed that the result of this effort will motivate further research in this specific field. As stated earlier, this research focused not only on students but teachers of English language and head teachers as well. However, the conclusion is based on the results of the analysis and interpretation of the questionnaires, interviews, reading logs, teachers' log and tests. Extensive reading programs should be implemented in every school as a part of their curriculum and firmly supervised by the school's administration. It is important not only for vocabulary development but to also help student improve in other language areas such as grammar, reading, speaking and writing. Additionally, Devine (1987) stated that it exposes learners to general knowledge and makes learning more dynamic and motivating. He further expressed extensive reading from the perspective of English Language Teaching implementation as a supplementary class where a library scheme is attached to an English course in which learners are given enough time, support and materials to read at their own level and interest, can get as many books as they can without the pressure of examination or scoring, so that students have to compete against only themselves and it is the duty of the teacher to provide the motivation and proper guidance to ensure that the highest number of books are read in the available time. The sight words of vocabulary for the soft board should have quantity and variety instead of quality so that books are chosen based on pleasant appearance and significance to the pupil's lives rather than only on literary merit.

The problem arises from a serious fact that the focus of many reading classes is often on teaching language instead of reading. Texts are mostly employed as vehicles for presenting linguistic patterns or meanings in detail. However, in the real world, reading is a mean to an end of something but not an end in itself. It is always a 
focused activity and teachers must help students to identify these diverse purposes and to practice the strategies that are best suited to achieve them. In short, reading lessons should be utilized to increase the reading proficiency of students instead of improving their linguistic competence. If the school library is stocked with relevant books and other pleasure reading materials, like novels, magazines, story books and plays, it will resemble the Book Flood Approach. In addition, schools should ensure a suitable environment for reading. With all of these efforts, the students will be encouraged not only to read but to build up reading culture. Students must appreciate the endeavors of their school, parents and teachers and focus on the main reason of their presence in school which is acquiring knowledge which can only be accomplished through reading both intensively and extensively. The lost reading habits of students must be picked up again which were replaced with internet browsing, playing computer games and watching television. Everyone in education such as the private schools owners, government and parents have a role to play. They must make supervising teacher-training programs and providing in-service training opportunities for the teachers and trainers. The next more important thing is to make sure that teachers are paid well so they put their efforts joyfully for the learners.

In the early stages, students should learn to read and have access to a variety of interesting materials which are essential for learners to develop lasting reading habits. However, if they have not acquired enough knowledge of a language and reading skills, they will not read on their own continually. However, if learners are given reading materials of their choice which appeal them it can create a situation where they will read with pleasure.

\section{Recommendations and Implications}

\subsection{Implications of the Study}

1). This research will provide help to other researchers who want to conduct studies relevant to extensive reading. They can also use these findings and retest them at primary or secondary level.

2). This research will be helpful for the institutes' administration to create not only an awareness of the importance of extensive reading but about its dire need in the present curriculum.

3). This research will help the administration department of the institutes to take this responsibility on their shoulders and cooperate with the teachers to enhance students' learning.

4). It can provide strong support for the value of extensive reading by using graded readers and other forms of extensive input such as authentic written material or, possibly, audio and video material.

\subsection{Recommendation}

The results of this research have indicated that extensive reading is valuable and any type of reading material which students read has a positive impact on language development. On the basis of this research, practical conditions and findings, the researcher tries to make some practical suggestions as follows:

\subsubsection{Extensive Reading as Part of a Syllabus}

This study supports the adoption of extensive reading in the school syllabus permanently. It should be realized that there are definitely many advantages of extensive reading especially in language learning and students must be encouraged to read extensively outside the classroom. Moreover, the treasure of reading will provide new but different horizons which can create positive context and the experience will make them a positive person. Graded readers have been widely used which provide controlled language and information. Many studies have demonstrated that authentic books or First Language (LI) books contribute a lot in target language learning. The importance of this material should be kept in mind and teachers must be conscious about potential books for language learning and the rich variety of First Language (LI) materials available to them to use as a teaching resource wherever it is required. Teacher must keep the features and level of the books in mind to attract the attention of the learners and maintain their interest.

\subsubsection{Training of the Learners}

There is a possibility that students may have used a bottom up approach for decoding texts due to a lack of certain skills which are important for extensive reading. When they read more books, they will come across many new words and things which they are not familiar with. To remove this problem, it is advisable to train the learner before starting the extensive reading program so that they should know the strategies and can use during and after reading and they must not discourage (Day \& Bamford, 2002).

\subsubsection{Promotion of Activities}

There were different activities as part of this extensive reading program such as discussions, role plays, summary writing, letter writing, guess who games and retelling stories. Because of these activities students were alert that 
they had to say or do something. These activities motivated many students who were not very good readers but they got the opportunity to discuss what they read or at least perform to satisfy their curiosity.

Extensive reading programs can only be effective if all things discussed above are kept in mind as they are all interlinked. If the book level is fine but no activities are undertaken, students are likely to forget and all efforts will go waste.

\subsection{Conclusion}

This study has said that extensive reading programs can successfully be implemented in a traditional learner setting. The impact of extensive reading on a learner's vocabulary enhancement and the purpose of creating a reading situation where students are able to choose books on their own and read for pleasure, meaning and understanding are obvious. Evidently, these cannot be accomplished by the intensive reading approach alone. Indisputably, extensive reading has obtained little consideration in the latest teaching situations. Extensive reading does help in the enhancement of vocabulary but teacher's watchfulness, school administration's support and students' enthusiasm, all are required to attain better results. Extensive reading is very important as it supplements intensive reading which can reduce the workload of both teachers and students. Students feel more motivated and are ready to learn when the advantages of extensive reading are explained in detail along with its rules and principles.

\section{References}

Bamford, J. (1987). Extensive reading using graded readers...and beyond. Presentation given at JALT Osaka chapter meeting, Osaka, Japan

Bamford, J., \& Day, R. (2004). Extensive reading activities for teaching language. Cambridge: Cambridge University Press.

Cunningham, A. E., \& Stanovich, K. E. (1998). The impact of print exposure on word recognition. In J. Metsala \& L. Ehri (Eds.), Word recognition in beginning literacy (pp. 235-262). Mahwah, NJ: Erlbaum.

Day, R., \& Bamford, J. (1998). Extensive Reading in the Second Language Classroom. Cambridge: Cambridge University Press.

Day, R. (2011). The benefits of extensive reading (ER). Retrieved November 22, 2012, from http://www.oupbookworms.com/downloads/pdf/successful_reading/er_article.pdf

Devine, J. (1987). General language competence and adult second language reading. In J. Devine, P. L. Carrell, \& D. E. Eskey (Eds.), Research in reading in English as a second language (pp. 73-86). Washington: TESOL.

Grabe, W. (1995). Dilemmas for the development of second language reading abilities. Prospect, 10(2), 38-51.

Hill, J. (1986). Teaching literature in the language classroom. London: Modern English Publications/Macmillan.

Hoey, M. (2005). Lexical Priming. London: Routledge. https://doi.org/10.4324/9780203327630

Krashen, S. (1989). We acquire vocabulary and spelling via reading: Additional evidence for the input hypothesis. Modern Language Journal, 73(4), 440-464. https://doi.org/10.1111/j.1540-4781.1989.tb05325.x

Krashen, S. (1993). The case for free voluntary reading. Canadian Modern Language Review, 50(1), 72-82.

Laufer, B. (1989). What percentage of text-lexis is essential for comprehension? In C. Lauren, \& M. Nordman (Eds.), Special language: From human thinking to thinking machines (pp. 316-323). Clevdon, England: Multilingual Matters.

Mutoh, N., Banford, J., \& Helgesen, M. (1998). Handout from the Extensive Reading Forum JALT. Omiya, Japan. Retrieved from http://www.extensivereading.net/JALT98.html

Maley, A. (2009). Kinds of Extensive Reading. Retrieved on 28November 2014 from https://www.teachingenglish.org.uk/article/extensive-reading-why-it-good-our-students\%E2\%80\%A6-us

Nation, I. S. P., \& Wang, M. K. (1999). Graded readers and vocabulary. Reading in a Foreign Language, 12, 355-379.

National Reading Panel. (2000). Teaching children to read: An evidence-based assessment of scientific research literature on reading and its implications for reading instruction. Bethesda, MD: National Institutes of Health.

Nuttall, C. (1996). Teaching reading skills in a foreign language. (2nd ed.). London: Heinemann.

Paribakht, T., \& Wesche, M. (1993). The relationship between reading comprehension and second language development in a comprehension-based ESL program. TESL Canada Journal, 11(1), 9-29. 
https://doi.org/10.18806/tesl.v11i1.623

Paribakht, T. S., \& Wesche, M. (1996). Enhancing vocabulary acquisition through reading: A hierarchy of text-related exercise types. The Canadian Modern Language Review, 52(2), 155-178.

Pigada, M., \& Schmitt, N. (2006). Vocabulary acquisition from extensive reading: A case study. Reading in a Foreign Language, 18(1), 1-28.

Stahl, S. A., \& Kapinus, B. (2001). Word power: What every educator needs to know about teaching vocabulary. Washington, D.C.: National Education Association.

Smith, F. (1985). Reading without nonsense. New York: Teachers College Press.

Susser, B., \& Robb, T.N. (1989). Extensive homework. The Language Teacher, 13(8), 7-9.

Waring, R. (2009). The Inescapable case for Extensive Reading. Retrieved December 10, 2014, from $\mathrm{http}: / /$ www.robwaring.org/er/what_and_why/er_is_vital.htm

Webb, S., \& Chang, A. C. S. (2015). How does prior word knowledge affect vocabulary learning progress in an extensive reading program? Studies in Second Language Acquisition, 37(4), 651-675. https://doi.org/10.1017/S0272263114000606

\section{Appendix A}

\section{Vocabulary Knowledge Scale to aid}

\section{Vocabulary development}

1) I don't remember having seen this word before

2) I have seen this word before but I don't know what it means

3) I have seen this word before and I think it means (synonym or translation)

4) I know this word. It means (synonym or translation)

5) I can use this word in a sentence. e.g.:

You are required to put a tick on the right box according to the key mentioned above.

\begin{tabular}{|l|l|l|l|l|l|l|}
\hline No. & Words & I & II & III & IV & V \\
\hline 1. & Shore & & & & & \\
\hline 2. & Shipwreck & & & & & \\
\hline 3. & Oar & & & & & \\
\hline 4. & Uninhabitable & & & & & \\
\hline 5. & Canvas & & & & & \\
\hline 6. & Raft & & & & & \\
\hline 7. & Natives & & & & & \\
\hline 8. & Cannibals & & & & & \\
\hline 9. & Hollow & & & & & \\
\hline 10. & Ammunition & & & & & \\
\hline 11. & Tame & & & & & \\
\hline 12. & Compasses & & & & & \\
\hline 13. & Enclosure & & & & & \\
\hline 14. & Candlewick & & & & & \\
\hline 15. & Barley husk & & & & & \\
\hline 16. & Sown & & & & & \\
\hline 17. & Ripe & & & & \\
\hline
\end{tabular}




\begin{tabular}{|l|l|l|l|l|l|l|}
\hline 18. & March & & & & & \\
\hline 19. & Hedge & & & & & \\
\hline 20. & Undamaged & & & & & \\
\hline 21. & Twigs & & & & & \\
\hline 22. & Meat pie & & & & & \\
\hline 23. & Flock & & & & & \\
\hline 24. & Stockings & & & & & \\
\hline 25. & Goatskin & & & & & \\
\hline 26. & Knot & & & & & \\
\hline 27. & Idle & & & & & \\
\hline 28. & Doubt & & & & & \\
\hline 29. & Mainland & & & & & \\
\hline 30. & Homicide & & & & \\
\hline
\end{tabular}

\section{Appendix B}

\section{Post Vocabulary Knowledge Scale}

\section{[to aid Vocabulary development]}

6) I don't remember having seen this word before

7) I have seen this word before but I don't know what it means

8) I have seen this word before and I think it means (synonym or translation)

9) I know this word. It means (synonym or translation)

10) I can use this word in a sentence. e.g.:

You are required to put a tick on the right box according to the key mentioned above.

\begin{tabular}{|l|l|l|l|l|l|l|}
\hline No. & Words & I & II & III & IV & V \\
\hline 1 & previous & & & & & \\
\hline 2 & Canoe & & & & & \\
\hline 3 & Anxious & & & & & \\
\hline 4 & decision & & & & & \\
\hline 5 & Sore & & & & & \\
\hline 6 & Prisoners & & & & & \\
\hline 7 & dramatic & & & & & \\
\hline 8 & manner & & & & & \\
\hline 9 & Drunk & & & & & \\
\hline 10 & Sea Shore & & & & & \\
\hline 11 & task & & & & & \\
\hline 12 & Arrow & & & & & \\
\hline 13 & indisputable & & & & & \\
\hline 14 & astute & & & & & \\
\hline 15 & ferry & Natives & & & & \\
\hline 16 & herbivorous & & & & \\
\hline 17 & & & & & \\
\hline
\end{tabular}




\begin{tabular}{|l|l|l|l|l|l|l|}
\hline 18 & Hollow & & & & & \\
\hline 19 & comparison & & & & & \\
\hline 20 & Tame & & & & & \\
\hline 21 & upright & & & & & \\
\hline 22 & sane & & & & & \\
\hline 23 & misunderstand & & & & & \\
\hline 24 & instructions & & & & & \\
\hline 25 & hurts & & & & & \\
\hline 26 & captives & & & & & \\
\hline 27 & Sight- seeing & & & & & \\
\hline 28 & Lag behind & & & & & \\
\hline 29 & strive & & & & & \\
\hline 30 & ferocious & & & & & \\
\hline
\end{tabular}

\section{Copyrights}

Copyright for this article is retained by the author(s), with first publication rights granted to the journal.

This is an open-access article distributed under the terms and conditions of the Creative Commons Attribution license (http://creativecommons.org/licenses/by/4.0/). 